\title{
Diagnosis and management of benign ovarian tumors at the Ignace Deen Maternity Hospital of Conakry University Hospital in Guinea
}

\author{
Abdourahamane Diallo1,2*, Ibrahima Koussy Bah ${ }^{1,2}$, Aboubacar Sidiki Magassouba², \\ Mamadou Cellou Diallo ${ }^{1,2}$, Telly Sy ${ }^{1,2}$
}

\begin{abstract}
${ }^{1}$ Department of Gynecology-Obstetrics of the Ignace Deen National Hospital of Conakry University Hospital, Guinea ${ }^{2}$ Faculty of Health Sciences and Techniques of Gamal Abdel Nasser University of Conakry, Guinea
\end{abstract}

Received: 13 December 2019

Accepted: 06 January 2020

\section{*Correspondence:}

Dr. Abdourahamane Diallo,

E-mail: adiallo69gn@gmail.com

Copyright: () the author(s), publisher and licensee Medip Academy. This is an open-access article distributed under the terms of the Creative Commons Attribution Non-Commercial License, which permits unrestricted non-commercial use, distribution, and reproduction in any medium, provided the original work is properly cited.

\begin{abstract}
Background: Benign ovarian tumors are a common reason for consultation and intervention in gynecology. The objective of this was to describe the clinical, ultrasonographic, histological and therapeutic aspects of benign ovarian tumors in the department.

Methods: This is a retrospective and descriptive study of three years and six months from January 1, 2016, to June 30, 2019, which focused on the records of women-operated during this period of benign ovarian tumors.

Results: The incidence of benign ovarian tumors was $12.58 \%$. The circumstances of discovery were dominated by disorders of the menstrual cycle $(35.05 \%)$ followed by infertility $(20.78 \%)$, the sensation of a pelvic mass $(19.48 \%)$, and pelvic pain. (15.58\%). The ultrasound report was in favor of a serous cyst in $74 \%$ of cases, a mucoid cyst in $14 \%$ of cases, a dermoid cyst in $9 \%$ and an endometriotic cyst in 3\%. Histology revealed a serous cystadenoma in $70.13 \%$ of the cases, a mucinous cystadenoma in $16.88 \%$ of the cases, a mature poly tissue teratoma in $9.09 \%$ of the cases and an endometrial cyst in $3.90 \%$ of the cases. Cystectomy was the most performed surgical procedure $(71 \%)$.

Conclusions: Benign ovarian tumors are common in our practice. The most common histological forms were serous and mucinous cystadenomas. Conservative treatment has been practiced in the majority of cases.
\end{abstract}

Keywords: Benign ovarian tumors, Conakry, Diagnosis, Ignace deen, Management

\section{INTRODUCTION}

Benign ovarian tumors are a common reason for consultation and intervention in gynecology. ${ }^{1,2}$

Their prevalence is estimated between 14 and $18 \%$ in postmenopausal women and around $7 \%$ in asymptomatic women during periods of genital activity. Their incidence during pregnancy is between 0.2 and $5 \% .^{3}$ In pre-pubes and adolescent girls, the prevalence of ovarian cysts greater than $2 \mathrm{~cm}$ ranges from 1 to $12 \% .^{4}$ Their onset may depend on numerous medical treatments, whether they are contraceptives (appearance or prevention of their appearance), endocrinological (stimulator of ovulation, hormonal therapy), or independent of gynecological pathologies (immunosuppressors). ${ }^{3}$

These cysts may be the origin of symptoms due to their natural evolution or the occurrence of complications. ${ }^{5}$ The most common complications are torsion, rupture, mechanical compression of neigh-boring organs, intracystic hemorrhage. ${ }^{2,6}$ The risk of recurrence after 
treatment is between 1 and $19 \% .{ }^{5}$ Ovarian cysts may have a consequence of female fertility. Still, therapeutic strategies are more infertile than the histological nature of the cyst in young women. ${ }^{7}$ Benign ovarian tumors may be associated with an increased long-term risk of mucinous ovarian cancer. ${ }^{8}$ In contrast, some authors report that malignant transformation of an ovarian cyst is very rare and that women with ovarian cysts of benign appearance have no increased risk of cancer. ${ }^{5}$ Although pelvic ultrasound is the first-line examination in the diagnosis of ovarian tumors, it does not differentiate benign malignancy with $100 \%$ reliability. Only histological examination leads to the conclusion of the benignity of an ovarian tumor..$^{9,10}$

In terms of surgical management, ovarian cystectomy, ovariectomy or adnexectomy are the standard surgical techniques for benign tumors. ${ }^{11}$

What about the diagnosis and management of benign ovarian tumors in the department?

In the absence of a previous study to answer this question, it was proposed to carry out this study whose objective is to describe the clinical, ultrasonographic, histological, and therapeutic aspects of benign tumors of the ovary in the department.

\section{METHODS}

This is a retrospective study and descriptive of three years and six months from $1^{\text {st }}$ January 2016 to $30^{\text {th }}$ June 2019. The study concerned the records of women operated on during this period of benign ovarian tumor.

\section{Inclusion criteria}

- All the files of women operated on for benign ovarian tumors containing the report of the histological examination of the surgical specimen were included in the study.

\section{Exclusion criteria}

- All non-usable files have been excluded.

We carried out an exhaustive recruitment of all the files meeting the inclusion criteria.

The data was collected by examining the various files selected and reported on the previously established survey form.

The evaluation focused on the socio-demographic characteristics of women (age, parity, marital status, occupation, educational level), the circumstances of discovery, the report of ultrasound and histological examinations, and management.

\section{Statistical analysis}

The data were analyzed with the R-software (version 3.4.2). The descriptive analysis consisted of calculating proportions for the qualitative variables, means, standard deviations, and extremes for the quantitative variables.

\section{RESULTS}

Frequency of benign ovarian tumors in the department: during this period, 77 files were identified that met the selection criteria among the 612 gynecological interventions performed in the department, i.e., a frequency of $12.58 \%$.

\section{Sociodemographic characteristics}

The mean age of the patients was $30.7 \pm 5.1$ years, the extremes of 18 and 55 years, and the range of 21 to 40 years was the most affected $(82 \%)$. The average parity was $2.1 \pm 1.6$, with extremes of 0 to 7 years. The majority were out of school (60\%), married (75\%) and housewives $(51 \%)$ (Table 1$)$.

Table 1: Distribution of patients according to their socio-characteristics sociodemographic.

\begin{tabular}{|c|c|c|}
\hline Demographic characteristics & $\begin{array}{l}\text { Number } \\
(\mathrm{n}=77)\end{array}$ & $\%$ \\
\hline \multicolumn{3}{|l|}{ Age (years) } \\
\hline$\leq 20$ & 5 & 6.49 \\
\hline $21-25$ & 14 & 18,18 \\
\hline $26-30$ & 21 & 27.27 \\
\hline $30-35$ & 17 & 22.08 \\
\hline $36-40$ & 11 & 14.29 \\
\hline $41-45$ & 6 & 7.79 \\
\hline$>45$ & 3 & 3.90 \\
\hline \multicolumn{3}{|c|}{$\begin{array}{l}\text { Average age }=30.7 \text { standard deviation }=5.1 \\
\text { Extremes } 18 \text { and } 55\end{array}$} \\
\hline \multicolumn{3}{|c|}{ Parity } \\
\hline Nulliparous & 27 & 35.06 \\
\hline Primiparous & 22 & 28.57 \\
\hline Pauciparous & 18 & 23.38 \\
\hline Multiparous & 10 & 12.99 \\
\hline \multicolumn{3}{|c|}{$\begin{array}{l}\text { Parity Mean }=2.1 \text { standard deviation }=1.6 \\
\text { Extreme }=0 \text { and } 7\end{array}$} \\
\hline \multicolumn{3}{|c|}{ Level of education } \\
\hline Enrolled & 31 & 40.26 \\
\hline Not educated & 46 & 59.74 \\
\hline \multicolumn{3}{|l|}{ Occupation } \\
\hline Housewife & 39 & 50.65 \\
\hline Student/student & 11 & 14.29 \\
\hline Employee & 7 & 9.10 \\
\hline Liberal & 20 & 25.97 \\
\hline \multicolumn{3}{|l|}{ Marital status } \\
\hline Bride & 58 & 75.32 \\
\hline Single & 19 & 24.68 \\
\hline
\end{tabular}




\section{Circumstances of discovery}

Menstrual disorders ranked first with $35.05 \%$, followed by infertility $(20.78 \%)$, the sensation of pelvic mass $(19.48 \%)$, and pelvic pain (15.58\%) (Table 2).

Table 2: Distribution of patients according to the circumstances of discovery.

\begin{tabular}{|lcc|}
\hline Circumstances of discovery & Findings & $\%$ \\
\hline Pelvic pain & 12 & 15.58 \\
\hline Pelvic mass & 15 & 19.48 \\
\hline Menstrual cycle disorder & 27 & 35.06 \\
\hline Infertility & 16 & 20.78 \\
\hline Micturition disorders & 2 & 02.60 \\
\hline Fortuitous & 5 & 06.49 \\
\hline Total & $\mathbf{7 7}$ & $\mathbf{1 0 0 . 0 0}$ \\
\hline
\end{tabular}

Among the 16 patients received for infertility, 6 (37.50\%) returned to give birth in the department within two years of the procedure. The tumor was bilateral in 3 patients $(3.90 \%)$, and 5 patients $(6.50 \%)$ were received for recurrence of the tumor after the first intervention.

\section{Ultrasound report}

The ultrasound report was in favour of a serous cyst in $74 \%$ of cases, a mucoid cyst in $14 \%$ of cases, $9 \%$ of the dermoid cyst, and $3 \%$ of the endometriotic cyst. The size of the tumor varied from 10 to $19 \mathrm{~cm}$ in diameter (Table $3)$.

Table 3: Distribution of patients according to the ultrasound report.

\begin{tabular}{|lll|}
\hline Report & Number & $\%$ \\
\hline Serous cyst & 57 & 74.02 \\
\hline Dermoid cyst & 7 & 9.10 \\
\hline Mucoid cyst & 11 & 14.29 \\
\hline Endometriotic cyst & 2 & 2.60 \\
\hline Total & $\mathbf{7 7}$ & $\mathbf{1 0 0 . 0 0}$ \\
\hline
\end{tabular}

The size of the tumor varied from 10 to $19 \mathrm{~cm}$ on ultrasound.

Table 4: Distribution of patients according to histological result.

\begin{tabular}{|lll|}
\hline Result & Number & $\%$ \\
\hline Serous cystadenoma & 54 & 70.13 \\
\hline Mucinous cystadenoma & 13 & 16.88 \\
\hline Cyst endometrial & 3 & 3.90 \\
\hline Mature poly tissue teratoma & 7 & 9.09 \\
\hline Total & $\mathbf{7 7}$ & $\mathbf{1 0 0 . 0 0}$ \\
\hline
\end{tabular}

\section{Results of histological examination}

The examination revealed a serous cystadenoma of $70.13 \%$ of cases, a mucinous cystadenoma in $16.88 \%$ of cases, a mature poly tissue teratoma in $9 \%$ of cases, and an endometrial cyst in $3 \%$ of cases (Table 4 ).

\section{A surgical procedure performed}

Cystectomy was the most performed surgical procedure (71\%) followed by ovariectomy (16\%), adnexectomy $(10 \%)$, and hysterectomy with adnexectomy $(3 \%)$.

\section{Complications of the cyst}

There were five cases of torsion and two cases of compression of the lower urinary tract.

\section{Postoperative complications}

There were three cases of anemia (moderate and mild) and two cases of parietal suppuration.

Mean length of stay $3.2 \pm 1.4$ days with extremes of 2 and 7 days.

\section{DISCUSSION}

Benign ovarian tumors are the second leading cause of gynecological intervention in the department after uterine fibromyoma. About one in 10 operated patients is operated on for a benign ovarian tumor. The high prevalence of benign ovarian tumors in the interval from 21 to 40 years reported during this study was also found in the study by Fouedjio et al, at the Yaoundé Central Hospital. $^{2}$ Younger girls may be affected by this condition, as in this case of a 14-years-old pre-pubertal girl who underwent a benign mucinous cystadenoma of 9 kg. ${ }^{12}$ According to Mimoun et al, the prevalence of ovarian cysts in prepubertal girls is $5.4 \%$. $^{3}$

The socio-demographic profile of the victims is different from that reported in Yaoundé according to which single people $(73 \%$, students $(42 \%)$ and women in school $(100 \%)$ are the most frequent. ${ }^{2}$

These tumors were mainly discovered during a consultation for disorders of the menstrual cycle (amenorrhea, dysmenorrhea, anysomenrrhea), for infertility (primary and secondary) or for pelvic pain. On the other hand, in the study of Fouedjio, the pains constituted the first circumstance of discovery. ${ }^{2}$ In $6 \%$ of cases, the tumor was accidentally discovered during a routine examination in asymptomatic patients. This observation is similar to that of Laculle-Massin et al. ${ }^{9}$ At the end of the clinical examination, torsion of the cyst was suspected in 5 patients, which was confirmed during surgery, thus constituting the first complication as reported by some authors. ${ }^{13}$ Bottomley et al, found that cyst torsion accounted for $2.7 \%$ of all gynecological emergencies. $^{6}$ In contrast, Fouedjio et al, reported a predominance of cyst rupture $(36.40 \%)^{2}$ 
All patients had undergone a preoperative ultrasound. The reports had reported no malignancy criteria for all cases. This testifies to the excellent performance of ultrasound in the diagnosis of ovarian tumors even if it does not replace histology as reported by some authors..$^{9,10}$ The ultrasound/histology concordance is around 70 to $80 \% .^{10}$ The findings were most often in favor of a serous or mucoid cyst. Cases of bilateral tumors were rare, as well as recurrences following a first intervention.

Since the service had no laparoscopy, laparotomy was the only surgical method used, contrary to current recommendations that consider laparoscopy as the standard technique for the surgical management of benign ovarian tumors. ${ }^{14,15}$ In order to maintain the fertility of the patients, the cystectomy was performed whenever possible for women during periods of genital activity. This is consistent with the result of Fouedjio who reported $79 \%$ of cystectomy. ${ }^{2}$ Bourdel et al. suggest, before the menopause, that a conservative treatment is privileged outside an oncological antecedent. ${ }^{14}$ But, even a cystectomy can influence the subsequent fertility of the patients by decreasing the ovarian reserve or by creating adhesions that can hinder the uptake of the oocyte by the uterine tubes. ${ }^{4,7,14,16}$ Some authors propose, for the conservation of fertility, the freezing of ovarian tissues. ${ }^{13}$ Dadou et al, demonstrated the feasibility and proper adherence of patients to egg freezing. ${ }^{17}$

In this series, 4 patients out of 10 who were received for an ovarian tumor on an infertility site returned to give birth in the department within two years. According to some authors, failing to preserve fertility, the conservation of endocrine function is desirable in the premenopausal patients to not increase the risk of cardiovascular diseases in these women. ${ }^{14}$ For huge tumors with no obvious cleavage area and after checking the contralateral ovary, ovariectomy was performed. The adnexectomy was reserved for necrotic appendix twists and cases of recurrence with solid adhesions preventing the separation of the tumor from the rest of the appendix. Both cases of hysterectomy involved two women over 50 years of age with ovarian cysts, uterine myomas, and hydrosalpinx. The follow-up was complicated by 3 cases of moderate to mild anemia that did not require blood transfusion and two cases of parietal suppuration involving two obese women, one of whom was diabetic.

No histological examination was done in extemporaneous. All examinations were performed on the surgical specimens deposited in the anatomy pathology laboratory after the procedure. Histological examination revealed more frequently serous cystadenoma or mucinous cystadenoma. This finding is different from that of Dadoun et al, who report $50 \%$ of patients who had a dermoid cyst, $25 \%$ a mucinous cyst, and $25 \%$ of other patients an endometrioma. ${ }^{17}$ Akhras et al, reported the case of a 72-year-old woman who underwent a mucinous cystadenoma weighing $27 \mathrm{~kg} .{ }^{18}$
The patients' stay in the ward after the procedure was relatively brief, with an average stay of 3.2 days. Steady patients with reverted transit were released on the second or third postoperative day.

\section{CONCLUSION}

Benign ovarian tumors are common in our practice. Women aged 21 to 40 , out of school, married, and homemakers were the most affected. It was noted that there was good agreement between the ultrasound report and the histological result. Serous and mucinous cystadenomas were common. Laparotomy was the only surgical method used. Conservative treatment has been practiced in the majority of cases. Operative follow-ups were usually straightforward with a brief stay at the hospital after the procedure. The implementation of laparoscopic surgery and extemporaneous histological examination may improve the management of patients suffering from ovarian tumors in the department.

Funding: No funding sources

Conflict of interest: None declared

Ethical approval: The study was approved by the Institutional Ethics Committee

\section{REFERENCES}

1. Dimassi K, Bettaieb H, Derbel M, Triki A, Gara MF. Ovarian cysts: sonographic score of malignancy. The Pan African Med J. 2014;18:215.

2. Fouedjio JH, Fouelifack FY, Nnang NA, Mbu RE. Epidemiological, clinical and therapeutic aspects of presumed benign ovarian tumors at Yaounde Central Hospital. Pan African Med J. 2016;25(207):1-6.

3. Mimoun $\mathrm{C}$, Fritel $\mathrm{X}$, Falconer A, Deffieux $\mathrm{X}$, Dumont A, Huchon C. Epidemiology of suspected benign ovarian tumors. J Gynecol Obstet Biol Reprod. 2013;42:722-9.

4. Lansac J, Marret H. Ovarian tumors. In: Gynecology for the practitioner. $9^{\text {th }}$ ed. Paris: Elsevier Masson; 2018:205-19.

5. Deffieux X, Thubert $\mathrm{T}, \mathrm{Hu}$ Cchon, Demoulin $\mathrm{G}$, Rivain AL, Faivre E, et al. Complications of suspected benign ovarian tumors. J Gynecol Obstet Biol Reprod. 2013;42:816-32.

6. Bottomley C, Bourne T. Diagnosis and management of ovarian cyst accidents. Best Pract Res Clin Obstet Gynaecol. 2009;23:711-24.

7. Aubard Y, Poirot C. Ovarian tumors presumed benign and fertility. J Gynecol Obstet Biol Reprod. 2013;42:794-801.

8. Guleria S, Jensen A, Toender A, Kjaer SK. Risk of epithelial ovarian cancer among women with benign ovarian tumors: a follow-up study. Cancer Causes Control. 2019:1-7.

9. Laculle-Massin C, Collinet P, Faye N. Diagnostic strategies for suspected benign ovarian tumors. J Gynecol Obstet Biol Reprod. 2013;42:760-73. 
10. Marret H, Cayrol M. Ultrasound, and doppler in the diagnosis of presumed benign ovarian tumors. J Gynecol Obstet Biol Reprod. 2013;42:730-43.

11. Borghese B, Marzouk P, Santulli P, de Ziegler D. Surgical treatments of presumed benign ovarian tumors. J Obstet Reprod Biol. 2013;42:786-93.

12. Biçer S, Erkul Z, Demiryilmaz I, Peker N. A 9-kg ovarian mucinous cystadenoma in a 14-year-old premenarchal girl. Am J Case Rep. 2014;15:326-9.

13. Sevestre H, Ikoli JF, AL Thakfi W. Pathological anatomy and cytology of supposedly benign ovarian tumors. J Gynecol Obstet Biol Reprod. 2013;47:71521.

14. Bourdel N, Canis M. Therapeutic strategies of suspected benign ovarian tumors. J Gynecol Obstet Biol Reprod. 2013;42:802-15.

15. Mbaye M, Cissé ML, Kane Gueye SM, Faye Diemè $\mathrm{ME}$, Diouf AA, Guèye $\mathrm{M}$, et al. First results of gynecological coelioscopy at the University Hospital Of Dakar (CHU): prospective series of 128 cases. J Obstet Gynaecol Can. 2012;34(10):939-46.

16. Legendre G, Catala L, Morinière C, Lacoeuille C, Boussion F, Sentilhes L, et al. Relationship between ovarian cysts and infertility: what surgery and when? Fertil Steril. 2014;101(3):608-14.

17. Dadoun Y, Azais H, Keller L, d'Orazio E, Collinet P, Decanter C. Systematic proposal of fertility preservation by freezing of eggs in case of benign ovarian tumor. Obstet Gynecol Fertil Senol. 2017;57:1-7.

18. Akhras LN, Akhras LN, Faroog S, AlSebay L. A 27$\mathrm{kg}$ giant ovarian mucinous cystadenoma in a 72 year-old postmenopausal patient: a case report. Am J Case Rep. 2019;20:1601-6.

Cite this article as: Diallo A, Bah IK, Magassouba AS, Diallo MC, Telly S. Diagnosis and management of benign ovarian tumors at the Ignace Deen Maternity Hospital of Conakry University Hospital in Guinea. Int J Reprod Contracept Obstet Gynecol 2020;9:789-93. 